\title{
Economic Incentives and Foster Care Placement
}

\author{
Brian Duncan* and Laura Argys $\dagger$
}

\begin{abstract}
Using micro-level data on children entering foster care in 1998, we estimate how the financial compensation paid to foster caregivers affects the placement of foster children. Controlling for observable child and county characteristics as well as for unobservable state effects, our estimates indicate that a $\$ 100$ increase in the basic monthly foster care payment reduces the number of children placed in group homes by $28.7 \%$, with more children instead going to nonrelative foster homes. Further estimates indicate that the children moved out of group homes are equally likely to be placed in two-parent and single-parent homes, but they are disproportionately placed with caregivers who do not share the child's race or ethnicity. Finally, a $\$ 100$ increase in foster care payment will decrease the number of times the average child is moved from one foster placement to another by $20 \%$.
\end{abstract}

\section{JEL Classification: J130, I380}

\section{Introduction}

A large number of children in the United States spend time in foster care, separated from their biological parents. For example, in 1999, over 547,000 children lived in foster care, with an estimated 238,000 children entering the system in this year alone. ${ }^{1}$ Unable to remain in the care of their biological parents as a result of abuse or neglect, these children are placed in various foster care settings, including with members of their extended family, with unrelated foster families, or in group homes.

Care for foster children is supervised by state child welfare agencies and is subsidized by federal, state, and local dollars. Foster care providers receive a monthly payment on behalf of the child. In cases that meet the requirements of the foster care legislation in Title VI of the Social Security Act, the federal government shares much of the burden of foster care subsidization, although many children in foster care are not eligible for federal aid. Regardless of who foots the bill, states are granted latitude in determining the characteristics of their foster care programs, and as a result, licensing requirements for foster homes and compensation for

* Department of Economics, University of Colorado at Denver, Campus Box 181, Denver, CO 80217-3364, USA; E-mail Brian.Duncan@cudenver.edu; corresponding author.

$\dagger$ Department of Economics, University of Colorado at Denver, Campus Box 181, Denver, CO 80217-3364, USA.

The authors are grateful to Janet Currie, Terra McKinnish, Daniel Rees, and an anonymous referee for helpful suggestions. We would also like to thank Jennifer St. Peter and Vince Davis for their excellent research assistance. This study was funded by The National Institute of Child Health and Human Development (1 R03 HD049867-02).

Received July 2005; accepted September 2006.

${ }^{1}$ Authors' calculation from the Adoption and Foster Care Analysis and Reporting System. 
caregivers vary dramatically across states. ${ }^{2}$ For example, the basic foster care payment ranges from a low of just over $\$ 200$ per month to over $\$ 700$ per month.

In this article, we extract data on children who entered the foster care system in 1998 from the Adoption and Foster Care Analysis and Reporting System (AFCARS) data. We then link these data to state foster care regulations and subsidy rates. The combined data allow us to determine whether foster care subsidy rates and other foster care regulations affect the type of child placements that occur. Specifically, we examine the factors that determine a foster child's type of placement (i.e., with relatives, with an unrelated foster family, or in a group home), racial and ethnic match with his or her caretaker, placement with a two-parent family, and stability of the foster care experience (measured by the number of times the child is moved to a new placement within the first year).

In addition to a standard cross-sectional approach, we are able to control for state effects by exploiting the variation in foster care payments by the child's age. For example, in certain states, there is little difference in the basic foster care payments between two-year-olds and nine-year-olds. In other states, this difference is large. If one state's foster care payments are more generous for nine-year-olds, relative to two-year-olds, than another state's payments, are there also better foster care placements for nine-year-olds relative to nine-year-olds? Our stateeffects analysis uses the variation in payments across age, rather than across states, to identify the effect that foster care payments have on placement outcomes.

We find that more generous subsidy levels facilitate the placement of children in more desirable foster care settings. Specifically, our results indicate that a $\$ 100$ increase in the monthly basic foster care payment will reduce the likelihood that the average child will be placed in a group home by $7.1 \%$ and that the majority of children moved out of group homes will find placements with unrelated foster families. This result holds when we allow the estimates to vary by the child's age, gender, race/ethnicity, and disability status. The willingness of families to take in a related child (kinship care) is less sensitive to the amount of the foster care payment. Existing research on the relative merits of the various placement settings indicates that group residence is least beneficial for children, so shifting foster children into family settings by altering foster care subsidy levels could have important consequences for children.

Further estimates indicate that the children pulled from group homes through higher subsidies are equally likely to be placed in two-parent and single-parent homes, but they are less likely to be placed with caregivers who share the child's race or ethnicity, although these results are somewhat sensitive to the empirical specification. Finally, foster children with higher subsidies face a lower probability of removal from their initial placements. Our estimates indicate that a $\$ 100$ increase in the basic monthly foster care payment reduces the number of times a child is moved from one foster placement to another by $20 \%$. Allowing this estimate to vary by age indicates that increasing the foster care payment has a slightly larger effect on the placement stability of older children compared to younger children.

\footnotetext{
${ }^{2}$ Child welfare agencies are either state-administered or county-administered. In the latter case, basic foster care payment rates may also vary within states across counties.
} 


\section{The Foster Care System}

State child welfare agencies are charged with providing board and maintenance for children removed from their homes either by voluntary agreement or by court order. To meet the federal funding requirements for foster care, a child remanded to the care of a child welfare agency must be placed in a foster family home (a relative or nonrelative family that has been approved by the state) or a "child care institution" (a public or nonprofit child care institution that is approved by the state to care for no more than 25 children). The state, often with contributions from the federal government, provides monthly subsidies to the families or institutions providing care for a foster child.

Federal government participation in the foster care system has its roots in the 1935 Social Security Act that established the program eventually referred to as Aid to Families with Dependent Children (AFDC). It was not until the 1961 Flemming Ruling, however, that the use of federal funds for children had been removed from their homes was approved (Ross and Cahn 2000). This ruling authorized foster care providers to receive child-only AFDC payments in cases in which the child's family of origin would have qualified for AFDC. Since that time, many states have increased their foster care subsidies to levels substantially higher than the child-only AFDC payment. In 1996, more than half of the states (26) had foster care payments in excess of the corresponding welfare benefit (Boots and Geen 1999).

Monthly payments from the state to foster care providers vary across states, and some states further devolve the responsibility to the county level. Most states provide a basic foster care rate that varies based on the age of the child. In addition, many states supplement their basic rates according to the special medical or emotional needs of the child. ${ }^{3}$ Mirroring estimates of family expenditures on children, the basic monthly subsidy levels, for the most part, increase with age. The 1998 basic foster care subsidy rates in 34 states for children aged 2 , 9, and 16 years are shown in Table $1 .{ }^{4}$ Caretakers of teenaged foster children receive, on average, nearly $\$ 72$ more per month than those caring for very young children, and there is substantial variation in basic foster care subsidies across states. For instance, the minimum payment for a two-year-old is $\$ 212$ in South Carolina, compared to the maximum of $\$ 622$ in Connecticut. Typically states designate age ranges and set one basic monthly subsidy rate for children under the age of five or six years; another, usually higher rate for children between the ages of about 6 and 12 years; and a higher rate yet for children over the age of 11 or 12 years. However, not all states increase payments with age. In six states, basic monthly subsidy rates are identical for children of all ages, and in two other states, subsidy levels actually decrease with age for some age groups.

In the empirical analysis below, we exploit the variation in basic foster care payments across states and within states across age groups to examine the effect of subsidies on the type of foster care placement as well as on the number of placements a child experiences while in foster care.

\footnotetext{
${ }^{3}$ Caregivers and public caseworkers often negotiate payments on a case-by-case basis. Additional payments may be granted for special needs or treatment in group facilities. In our analyses we use the basic monthly subsidy rate. Variation in negotiated rates across states will be captured by the inclusion of state effects.

${ }^{4}$ Forty-one states participated in the State Child Welfare Agency Survey conducted by the Child Welfare League of America (1999). The additional data restrictions are described in section 6.
} 
Table 1. State Basic Monthly Foster Care Payments in 1998 for Children Aged 2, 9, and 16 Years

\begin{tabular}{|c|c|c|c|}
\hline \multirow[b]{2}{*}{ State Name } & \multicolumn{3}{|c|}{ Child's Age } \\
\hline & 2 Years & 9 Years & 16 Years \\
\hline Alabama & 230 & 254 & 266 \\
\hline Arizona & 408 & 397 & 447 \\
\hline Arkansas $^{\mathrm{a}}$ & 400 & 425 & 475 \\
\hline California & 345 & 400 & 484 \\
\hline Connecticut & 622 & 642 & 708 \\
\hline Delaware & 397 & 397 & 511 \\
\hline Georgia & 338 & 338 & 338 \\
\hline Hawaii & 529 & 529 & 529 \\
\hline Idaho $^{\mathrm{a}}$ & 228 & 250 & 358 \\
\hline Illinois & 343 & 382 & 415 \\
\hline Iowa & 387 & 409 & 474 \\
\hline Louisiana & 331 & 365 & 399 \\
\hline Maine $^{\mathrm{a}}$ & 438 & 447 & 501 \\
\hline Maryland & 535 & 535 & 550 \\
\hline Minnesota & 458 & 458 & 561 \\
\hline Mississippi $^{\mathrm{a}}$ & 325 & 355 & 390 \\
\hline Missouri & 316 & 364 & 392 \\
\hline Montana $^{\mathrm{a}}$ & 415 & 415 & 507 \\
\hline New Jersey & 351 & 369 & 439 \\
\hline New Mexico ${ }^{a}$ & 308 & 341 & 367 \\
\hline North Carolina & 315 & 365 & 415 \\
\hline North Dakota ${ }^{a}$ & 317 & 359 & 469 \\
\hline Oklahoma & 300 & 360 & 420 \\
\hline Oregon & 346 & 360 & 444 \\
\hline Rhode Island & 308 & 285 & 348 \\
\hline South Carolina & 212 & 239 & 305 \\
\hline Texas & 482 & 482 & 482 \\
\hline Utah & 319 & 319 & 319 \\
\hline Vermont $^{\mathrm{a}}$ & 360 & 360 & 440 \\
\hline Virginia $^{a}$ & 270 & 316 & 400 \\
\hline Washington & 313 & 374 & 468 \\
\hline West Virginia $^{a}$ & 400 & 400 & 400 \\
\hline Wisconsin & 289 & 315 & 374 \\
\hline Wyoming $^{\mathrm{a}}$ & 400 & 400 & 400 \\
\hline Average & 363 & 383 & 435 \\
\hline Minimum & 212 & 239 & 266 \\
\hline Maximum & 622 & 642 & 708 \\
\hline
\end{tabular}

Source: Data obtained from the Child Welfare League of America's 1999 State Child Welfare Agency Survey.

a States without any counties containing more than 1000 AFCARS foster care records in 1998.

\section{Economic Incentives and Foster Care Placement}

Researchers examining the effect of economic incentives on foster care outcomes typically have focused on the response of foster care providers to variation in the subsidy rates. Simon (1975) notes that the relationship between foster care placements and foster care payments can be explained by a change in the quantity of foster children demanded. Specifically, when "foster payments go up, the 'price' of a child ... goes down and the quantity of children demanded may 
be expected to rise" (Simon 1975, p. 406). This relationship could be expected to hold whether the foster provider was a relative, an unrelated foster family, or the administrator of a group home.

Three studies have examined the response of foster care providers to subsidy levels. In one of these studies, Campbell and Downs (1987) used cross-state variation in subsidy rates to explain differences in the supply of family foster care, measured by the number of children taken into each family foster home. Using data from a 1980 survey of over 1000 licensed foster family homes in eight states, the authors find a positive, but statistically insignificant, relationship between the subsidy rate and the number of children in each foster home. Because this study did not identify changes in the number of available foster family homes, however, one cannot conclude that subsidy rates have no effect on the overall availability of family foster care.

In the two other studies, researchers using aggregate data were able to include a wider cross section of states, multiple time periods, and measures of the number of foster care placement sites to estimate the sensitivity of the overall supply of foster care homes to changes in subsidy levels. Simon (1975) analyzed data from 38 states and the District of Columbia at three points in time between 1959 and 1968 . He regressed the ratio of children in foster care to the state population on the average payment per foster care child. ${ }^{5}$ Results from cross-sectional models in each of the three years yield estimates of the elasticity of the supply of foster homes of between zero and 0.68 . Recognizing that cross-sectional estimates are potentially biased by differences across states, Simon reestimated the models using differences within states over time. These estimates, however, were inconclusive, resulting in both positive and negative elasticities of the supply of foster care homes. Data limitations and the inconsistencies in his estimates leave doubt about the supply response to higher foster care subsidies. More recently, Doyle and Peters (2002) created a panel of annual state-level data for 37 states between 1987 and 1995 to address this question. Their model allows for the possibility that foster care markets in some states may not clear; that is, that there may be a shortage of foster families at the prevailing subsidy level. Estimating state fixed-effects models produces results indicating that higher subsidies bring forth a larger supply of foster homes. Specifically, Doyle and Peters find that higher subsidy levels are necessary to clear the foster care market in states with a larger demand for foster care services.

Very few studies have examined the relationship between foster care subsidy rates and the characteristics of foster care placement. Chamberlain, Moreland, and Reid (1992) conducted an experiment with 72 foster children in Oregon; the experiment was designed to assess the impact of two treatments on turnover in the foster care system. The control group received the usual state foster care subsidy. One treatment group of foster caretakers was provided an increased subsidy; a second treatment group was provided the increased subsidy combined with foster care training. The dropout rate for foster parents in the control group was significantly higher and the retention rate for children in the control group was significantly lower than the rates in the two treatment groups. That is, children were more likely to run away or be placed in a new foster home or in group care when subsidies were less generous. Another more recent study

\footnotetext{
${ }^{5}$ Analysis of foster care data in this early period is complicated by the fact that in 1959 a researcher could not distinguish foster children placed in institutional settings from those placed with a foster family. In addition, Simon's subsidy rate variable does not precisely measure the payments to foster families, since it is calculated from annual state foster care expenditures divided by the number of children in foster care.
} 
examined the effect of payment generosity on the probability of placement of foster children with relatives. Doyle's (2004) analysis of reform in Illinois that reduced the subsidization of foster care provided by relatives indicates that the $30 \%$ reduction in payments reduced the availability of kin care by over $15 \%$.

Taken together, the previous literature in this area indicates that policy makers have some leverage not only to increase the supply of foster homes but also to improve the quality of care for children placed in a family setting. However, this latter result is based on a small regional sample and examination of only one type of foster care setting, raising the question of whether these results are generalizable to the national foster care population. In the analyses that follow, we examine whether the generosity of foster care subsidies alters the type and stability of placements using a national sample of children in foster care.

\section{Priorities in Foster Care Placement}

When children are removed from their homes as a result of abuse or neglect or at the request of the parent, state child welfare agencies are charged with developing a foster care case plan that is in the best interests of the child. Based on the circumstances of the child's removal and the characteristics of the family and child, the agency may determine that reunification is the primary goal. However, if circumstances dictate, the state may move to place the child in a more permanent setting (one leading to adoption) or to place the child with a relative, with a family, or in a group setting for temporary or long-term care.

Legal scholars and policy makers have debated priorities in foster care policies for the past three decades and began adopting legislation emphasizing the undesirability of foster care as a permanent solution (Guggenheim 1999). The Adoption and Child Welfare Act of 1980 addressed some of these concerns by providing federal guidelines for state child welfare agencies by mandating that foster care should be the option of last resort and that "reasonable efforts" should be made to preserve or reunify the family (Lowery 2000). Legal scholars have urged that children entering foster care be placed in the least restrictive environment (Mnookin 1973; Wald 1975). In keeping with this principle, children would be placed with a family rather than in a group setting whenever possible. By the 1990s the focus of foster care policy recommendations began to emphasize adoption if reconciliation could not be effected quickly. ${ }^{6}$ The shift in philosophy became evident with the passage of the Adoption and Safe Families Act of 1997, which allowed states to move to terminate parental rights in a relatively brief period of time, rather than providing services for families in crisis and working toward reunification (Pagano 1999). These laws, in combination with the Coats Amendment of 1996, which mandated that preference be given to placements with an adult relative, indicate that state agencies look first to place children in preadoptive homes or with relatives. Placement with nonadoptive families was viewed as an acceptable alternative, and placement in a group setting was the alternative of last resort.

Which type of placement is best for children is an important question, one that is difficult to answer. Several studies have investigated the consequences of foster care placement

\footnotetext{
${ }^{6}$ Congress urged states to terminate parental rights if reunification had not occurred within 15 months of entering foster care (Pagano 1999).
} 
(Festinger 1983; Berrick 1997; Buehler et al. 2000). Studies have found that kinship caregivers are often older and more likely to be unmarried women of color, to have lower incomes, and to report more frequent health problems than are unrelated foster caregivers (Kelley 1992; Berrick 1997). Despite these apparent disadvantages, there is also evidence indicating that kinship care may confer some benefits. Foster children placed with relatives are more likely to reunite with parents, to have fewer total foster care placements, and to exhibit a lower probability of return to foster care after removal. Children in kinship settings, however, tend to remain in foster care longer and are less likely to resolve their foster care stay via adoption (Berrick 1997).

Many researchers have focused on the long-term consequences of foster care, although they typically compare children in foster care to children who have never been removed from their homes. ${ }^{7}$ The exception is a study by Festinger (1983) that analyzed later-life outcomes for children in family foster care and children in institutional foster care compared to children in the general population. The findings from this study indicate that adults who were placed in group homes as adolescents have lower educational attainment, lower employment probabilities, and report lower self-esteem and happiness than do similar adults raised in foster family homes. ${ }^{8}$ These findings are consistent with the preferences policy makers have expressed for family foster care placement over placement in a group setting.

\section{Empirical Model}

Our empirical model begins with a child's entry into the foster system. Ostensibly, the social service caseworker's goal is to place each child in the most beneficial setting based on availability of homes and on the child's individual circumstances. Although there are children who are too violent or unmanageable to be placed in a family setting, in general, placing a child with relatives or with an unrelated family is preferred to placing a child in a group home or institution. Our empirical analysis examines the degree to which the availability of foster care by relatives and other families responds to the level of foster care subsidies.

We assume that from the caseworker's perspective, children exogenously enter the foster care system. This assumption will be violated if states decide to remove children from their parents based, in part, on the availability of a particular type of foster care home. Previous studies, however, indicate that there is not an overall shortage of available foster homes. In a study of eight states, Campbell and Downs (1987) estimate that $27 \%$ of all licensed foster care homes are vacant at any point in time. Vacancy rates ranged from $43 \%$ in Arkansas to $18 \%$ in Wisconsin. Our analysis allows us to control for child characteristics, including the reason the child was removed from his or her home. Many of these reasons, such as the death of the parent, leave the state with no choice but to remove the child.

In most cases, foster parents are matched with foster children through negotiation between the caseworker and the potential foster care provider. The caseworker may find it difficult to place a child with certain characteristics in a foster home, not because there are no homes available, but because of the difficulty in finding a match between the needs of the child and the willingness and characteristics of the foster parent. For example, a two-parent household with

\footnotetext{
${ }^{7}$ See Buehler et al. (2000) for an excellent summary of this literature.

${ }^{8}$ These studies do not definitively establish a causal link between group care and poor outcomes because none control for the potential selection of low-achieving children into group homes.
} 
children may be an ideal match for many foster children. However, if the foster child is aggressive toward his or her siblings and/or peers, then the caseworker may determine that the child is better suited for a family without children. A child that has issues with a male or a female authority figure may be better suited to a single-parent home. Thus, a child on the margin between being placed in a group home or with a foster family may not be the typical foster child. Foster care payments can increase the availability of foster homes at the margin by reducing the cost and, thus, increasing the incentive to accept a foster child.

When child $i$ enters the foster care system, he or she is placed in setting $j$. We define placement outcomes in three ways. The first indicates the type of placement and is defined as

$$
J_{1}=\{\text { kinship, foster, group }\}
$$

where kinship represents the home of one of the child's relatives, foster represents a nonrelative family home, and group represents a group home or institution. As previously discussed, the relative merits of kinship and foster care are subject to debate, but there is wide consensus that group is the least desirable placement setting for most children. The second set of placement outcomes captures whether the child is placed with a family that shares his or her race or ethnic identity and is defined as

$$
J_{2}=\{\text { match, no match, unknown, group }\},
$$

where match means that at least one of the child's caregivers is known to be of the same race or Hispanic origin as the child, no match means that all of the child's caregivers are of a different race or Hispanic origin than the child, and unknown means the race and ethnicity of the child's caregivers is missing. We assume that a child placed with his or her relatives shares the same race or ethnicity. ${ }^{9}$ Children placed in group homes have no assigned caregiver, and so group remains as a fourth placement setting. The third set of placement outcomes captures the family structure into which a child is placed. The outcomes are defined as

$$
J_{3}=\{\text { couple, single, unknown, group }\} \text {, }
$$

where couple refers to a two-parent family (married or unmarried), single refers to a single male or female household, and unknown means that the household structure is not known. ${ }^{10}$

Given a set of placement outcomes, the multinomial logit model defines the probability that a randomly drawn foster child will be placed in placement $j$ as

$$
P\left[y_{i}=j \mid J,(\mathbf{x}, \mathbf{s}, \mathbf{z}),(\beta, \gamma, \pi)\right]=\frac{\exp \left(\beta_{j}^{\prime} \mathbf{x}_{i}+\gamma_{j}^{\prime} \mathbf{s}_{i}+\pi_{j}^{\prime} \mathbf{z}_{i}\right)}{\sum_{k \in J} \exp \left(\beta_{k}^{\prime} \mathbf{x}_{i}+\gamma_{k} \mathbf{s}_{i}+\pi_{k}^{\prime} \mathbf{z}_{i}\right)} .
$$

The vector $\mathbf{x}_{i}$ represents a set of child characteristics, such as age, race, diagnosed disabilities, reasons for removal from the home, and a constant; $\mathbf{z}_{i}$ represents a set of county characteristics; and $\mathbf{s}_{i}$ represents the monthly basic foster care payment. Our variable of interest, the basic monthly foster care payment, varies within a state by the child's age. However, it is an aggregate policy variable in the sense that it does not vary among children who are the same age and who live in the same state. Estimating the effects of aggregate policy variables on micro-

\footnotetext{
9 In our data, many states do not identify the race or ethnicity of kinship caregivers.

${ }^{10}$ The overwhelming majority of single caregivers are women (85\%). In fact, nearly $32 \%$ of all foster children are placed with single women, making the homes of single women the most common placement setting.
} 
level data can lead to standard errors that are biased downwards (Moulton 1990). As a result, we correct the standard errors for clustering at the state/age group level in all of our multinomial logit regressions.

The basic foster care payment, $\mathbf{s}_{i}$, is represented in Equation 4 as a vector because, in addition to estimating the overall effect, we also estimate versions of Equation 4 allowing the effect of foster care payments to vary by child characteristics. This is accomplished by estimating separate models that interact the basic foster care payment with a specific child characteristic. For example, we estimate a model that interacts foster care payments with three age categories to examine if the basic foster care payment has a different effect on older children than on younger ones. We also estimate three additional models that interact the basic foster care payment with two gender categories, four race categories, and two disability categories, respectively.

The sign and significance of $\gamma_{j}$ indicates whether or not increasing basic foster care payments will increase or decrease the probability that a child will be placed in outcome $j$, relative to the base setting. In all of our multinomial logit regressions, the base outcome is group. However, the magnitude of $\gamma_{j}$ in these models can be difficult to interpret. For this reason, we report the marginal effect that a $\$ 100$ increase in the basic monthly foster care payments will have on the probability that a child will be placed in outcome $j$ as:

$$
\frac{\partial P\left(y_{i}=j\right)}{\partial s}=P\left(y_{i}=j\right)\left[\gamma_{j}-\sum_{k} P\left(y_{i}=k\right) \gamma_{k}\right]
$$

calculated at the mean of the independent variables. Thus, the marginal effects represent the change in the probability that a child with the average characteristics will be placed in outcome $j$, relative to all alternate settings. Calculated this way, the marginal effects across all $j \in J$ sum to zero.

To estimate the effect of foster care payments on the number of times a child is moved to a new placement during his or her first year in foster care, we estimate the ordinary least squares (OLS) regression, thus:

$$
\text { moves }_{i}=\delta \mathbf{s}_{i}+\Pi_{1} \mathbf{x}_{i}+\Pi_{\mathbf{2}} \mathbf{z}_{i}+\varepsilon_{i}
$$

where $\mathbf{s}_{i}, \mathbf{x}_{i}$, and $\mathbf{z}_{i}$ are defined as above and $\varepsilon_{i}$ represents a random error term. The number of moves to a new foster care placement is a count variable with a starting value of zero, and so we also estimate Equation 6 with a Poisson regression. Negative values of $\boldsymbol{\delta}$ indicate that an increase in the monthly basic foster care payment is associated with an increase in the stability of foster care placements. As in the multinomial logit regressions, we also estimate Equation 6 , allowing $\boldsymbol{\delta}$ to vary by the child's characteristics.

\section{Controlling for State Effects}

One concern with drawing conclusions about the effect of state-level policy variables, such as foster care subsidy rates, from a single time period is that the policy effect may be either obscured or magnified by underlying, often-unmeasured characteristics and attitudes within the state. For instance, if the residents of a particular state place a high value on caring for foster children, many more families might be willing to provide foster care, and their legislators may provide more generous foster care payments. The estimate of $\gamma$ from Equation 4 would then overestimate the effect of basic foster care payments on child placement. On the other hand, the endogeneity of foster care payments could work in the opposite direction. That is, in a state 
with few families willing to provide foster care, lawmakers could be forced to increase payment levels. This scenario would result in a downward bias in the estimate of $\gamma$.

To address the potential effect of state-level policy and attitudes, we estimate Equations 4 and 6 , including a set of state dummy variables to control for unobservable characteristics of the state. Although our data is cross-sectional, including state effects is feasible because foster care payments vary both by state and by the child's age. The estimates of $\gamma$ and $\boldsymbol{\delta}$ in the pooled regressions are identified through state and age variation, but because they do not control for unobservable state characteristics, they are susceptible to omitted variable bias. The regressions that include state effects control for unobservable state characteristics, but they identify $\gamma$ and $\boldsymbol{\delta}$ based on within-state variation. For example, if state A is more generous to 15 -year-olds relative to six-year-olds than is state $B$, then we should see better placements of 15 -year-olds relative to six-year-olds in state $\mathrm{A}$ than in state $\mathrm{B}$.

\section{Data}

Since 1995, states have been required to provide detailed information on each child in their foster care system, although only 14 states submitted data in 1995 (National Data Archive on Child Abuse and Neglect 2002). It was not until 1998 that the penalties associated with the AFCARS took effect, bringing the number of reporting states to $43 .{ }^{11}$ Our primary data source is an extract of children, aged 16 years and younger, entering foster care for the first time in 1998, as reported in the 1998 AFCARS Version 6 data. Children in an additional nine states were dropped because the state failed to report key information, such as the year the child entered foster care, or because the foster care payments in 1998 were not determined by the state. ${ }^{12}$ Although the AFCARS data contain information on children who are in supervised independent living situations, participating in trial home visits with their parents, in preadoptive homes, or who have run away, only a small percentage of foster children fall into these placement settings. ${ }^{13}$ In addition, many of the records for these children contain missing information. For these reasons, we do not include these children in our analysis of placement within the foster care system. An additional 4568 children were excluded as a result of missing gender (111), number of foster care placements (332), race (4107), or age (18). The resulting sample includes 92,078 children living in 34 states.

In addition to the state, the AFCARS data also identify the county in which the child entered foster care, provided that this county contains at least 1000 foster care records. For the subset of children with an identified county, we are able to append a host of county-level characteristics to the child-level data, such as the population density, racial and ethnic makeup of the county, socioeconomic indicators, crime rate, and unemployment data. Descriptions of these county characteristics and their means are reported in Appendix A. Doyle and Peters

${ }^{11}$ Louisiana, Massachusetts, Nebraska, Nevada, New Hampshire, Ohio, South Dakota, and Tennessee are not included in the 1998 AFCARS data.

${ }^{12}$ Children in Colorado, Indiana, Kansas, New York, and Pennsylvania are excluded because their subsidy rates are not set by the state. Children in Alaska, the District of Columbia, Florida, and Michigan are excluded because of missing data.

${ }^{13}$ The placement type indicates the child's final placement setting in 1998. Less than $1 \%$ of the sample who entered foster care in this year fall into the categories of preadoptive homes, supervised independent living, and runaway. About 5\% have returned to their families in a trial home visit, and an additional $2.8 \%$ do not indicate the type of placement. 
(2002) included in their model variables that represent the demand for foster care. These factors include measures of child poverty; single-parent households and births to teenage mothers; unemployment rates; and estimates of child abuse. Because they examined the determinants of the total quantity of children placed in foster homes, it is important in their work to control for factors of demand. In our model, we examine the probability that any one child already in the foster care system is placed in a particular setting. We assume that increased demand for foster care homes will reduce the probability that a foster child will be placed with a foster family, but rather than including the many factors that contribute to the demand for foster care, we include a single measure of demand: the ratio of foster care children in the county to the county population under the age of 18 years.

Table 2 reports the number of children in each county of our county subsample. Approximately $54 \%$ of the children in the full sample live in a county with at least 1000 AFCARS foster care records and, therefore, have their county identified. This county subsample includes 49,309 foster care children living in 67 counties in 23 states. ${ }^{14}$ We perform all of our analysis below on the full sample and on the county subsample. The county subsample analysis has the advantage of controlling for the county characteristics reported in Appendix A. However, nearly half of the sample is lost as a result of protection of confidentiality. Furthermore, the children remaining in the county subsample do not represent a random sample of foster children. By construction, these children entered foster care in large, more urbanized areas than did the children without county data. For this reason, the county subsample should not be considered a random sample of foster care children.

To capture the effect of economic incentives on foster care placement, we link the childlevel AFCARS data with measures of the basic monthly foster care subsidy rate by the respondent's age and state indicator. ${ }^{15}$ As reported in Table 3, the average basic foster care subsidy for the children in our full sample is $\$ 394$ per month. Foster care subsidies were highest among those in group homes. This pattern reflects the fact that children in group homes are substantially older and that foster care subsidies typically increase with age (as seen in Table 1).

We classify the children in our sample by their most recently reported placement setting. Table 3 reports the characteristics of our full sample and county subsample overall and by placement type. The most prevalent foster care setting for the children in our sample is a nonrelative family foster home (49.6\% in the full sample and $42.3 \%$ in the county subsample). These families must be licensed by the state to provide foster care. Relatives providing foster care, or kinship care, account for $24.9 \%$ of the placements for children in our full sample, while $25.4 \%$ are placed in group homes. As one might expect, older children are more likely to be placed in group homes than are younger children. For example, $55.6 \%$ of foster children over 12 years of age are placed in a group home, compared to $18.3 \%$ of children between the ages of 5 and 12 years and $9.0 \%$ of children younger than five years.

${ }^{14}$ Arkansas, Idaho, Maine, Mississippi, Montana, New Mexico, North Dakota, Vermont, Virginia, West Virginia, and Wyoming have no foster care children living in an identified county.

${ }^{15}$ We also include a variable that indicates the stringency of state licensing of kinship caregivers. Using data from a 1997 survey of state foster care administrators by the Urban Institute (Boots and Geen 1999), we classify states into three categories: states in which kinship caregivers (i) face less stringent licensing standards and receive full foster subsidies; (ii) face less stringent licensing but receive lower AFDC payments if they do not meet regular foster care requirements; and (iii) must meet regular foster care licensing requirements. We expect that relatives are most likely to become kinship caregivers in category (i) states and least likely in category (iii) states. However, our results (available from the authors upon request) do not indicate that lower payments to kinship caregivers reduce this form of care. Since they vary only at the state level, we cannot include them in our state effects model. 
Table 2. Sample Size by County

\begin{tabular}{|c|c|c|c|}
\hline County & Sample Size & County & Sample Size \\
\hline Jefferson, Alabama & 312 & Orleans, Louisiana & 114 \\
\hline Maricopa, Arizona & 1147 & Baltimore City, Maryland & 1352 \\
\hline Pima, Árizona & 709 & Hennepin, Minnesota & 1060 \\
\hline Alameda, California & 983 & Ramsey, Minnesota & 296 \\
\hline Butte, California & 306 & Jackson, Missouri & 502 \\
\hline Contra Costa, California & 649 & St. Louis, Missouri & 440 \\
\hline Fresno, California & 1292 & St. Louis City, Missouri & 596 \\
\hline Kern, California & 1118 & Camden, New Jersey & 334 \\
\hline Los Angeles, California & 7557 & Essex, New Jersey & 477 \\
\hline Orange, California & 1768 & Hudson, New Jersey & 132 \\
\hline Riverside, California & 1510 & Guilford, North Carolina & 254 \\
\hline Alameda, California & 2620 & Mecklenburg, North Carolina & 192 \\
\hline San Bernardino, California & 1303 & Oklahoma, Oklahoma & 958 \\
\hline San Diego, California & 2808 & Tulsa, Oklahoma & 566 \\
\hline San Francisco, California & 375 & Lane, Oregon & 152 \\
\hline San Joaquin, California & 475 & Marion, Oregon & 213 \\
\hline San Mateo, California & 196 & Multnomah, Oregon & 523 \\
\hline Santa Clara, California & 1221 & Providence, Rhode Island & 892 \\
\hline Shasta, California & 247 & Richland, South Carolina & 182 \\
\hline Stanislaus, California & 206 & Bexar, Texas & 341 \\
\hline Tulare, California & 536 & Dallas, Texas & 652 \\
\hline Ventura, California & 234 & Harris, Texas & 776 \\
\hline Fairfield, Connecticut & 418 & Travis, Texas & 230 \\
\hline Hartford, Connecticut & 678 & Salt Lake, Utah & 735 \\
\hline New Haven, Connecticut & 642 & King, Washington & 726 \\
\hline New Castle, Delaware & 386 & Pierce, Washington & 575 \\
\hline De Kalb, Georgia & 329 & Snohomish, Washington & 269 \\
\hline Fulton, Georgia & 65 & Spokane, Washington & 338 \\
\hline Honolulu, Hawaii & 694 & Yakima, Washington & 225 \\
\hline Cook, Illinois & 2896 & Dane, Wisconsin & 235 \\
\hline Kane, Illinois & 127 & Milwaukee, Wisconsin & 336 \\
\hline Lake, Illinois & 113 & & \\
\hline Peoria, Illinois & 200 & County sample & 49,309 \\
\hline St. Clair, Illinois & 107 & County not identified & 42,769 \\
\hline Winnebago, Illinois & 143 & & \\
\hline Polk, Iowa & 266 & Full sample & 92,078 \\
\hline
\end{tabular}

Source: Adoption and Foster Care Analysis and Reporting System (AFCARS) 1998, Version 6.

${ }^{a}$ The sample includes children 16 and under entering foster care for the first time in 1998. Children in supervised independent living, trial home visits, pre-adoptive homes, or who have run away are not included in the sample. Louisiana, Massachusetts, Nebraska, Nevada, New Hampshire, Ohio, South Dakota, and Tennessee are not included in the 1998 AFACRS data. Children in Colorado, Indiana, Kansas, New York, and Pennsylvania are excluded because their subsidy rates are not reported to be uniform within the state. Children in Alaska, District of Columbia, Florida, and Michigan are excluded because of missing data. An additional 4568 children are excluded due to missing gender (111), number of placements (332), race (4107), or age at first removal (18). Counties not identified in the AFCARS data are those with fewer than 1000 total foster care records.

Administrative data reported to AFCARS also include sociodemographic information, such as the child's date of birth, race, and ethnicity, as well as diagnoses of specific disabilities and the reason the child was removed from his/her home. Our sample includes children 16 years of age and younger entering foster care in 1998, and on average, these children were 7.57 years old when they entered foster care (6.84 years old for the county subsample). African-American and Hispanic children make up a disproportionate share of the children entering foster care: $29 \%$ and 
$18 \%$, respectively, in the full sample. These percentages are even greater in the county subsample, in which $35 \%$ of children are African-American and $26 \%$ are Hispanic. This is further evidence that the county subsample is not a random sample of children from the full sample.

Because we expect the increased needs of children with disabilities to be a factor in placing children with families, we include an indicator of child disability in our models. Child disabilities reported in the sample include mental, emotional, and physical disabilities. Including separate indicators for each disability does not change our results, so our models include a single indicator for any disability. Nearly $11 \%$ of the children in our full sample and $8 \%$ of the children in our county subsample have a diagnosed disability. According to the summary statistics, a child with a disability is no more likely to be placed in a group home than in a non-related foster family home. However, they are less likely to be placed with a relative.

Children in foster care are removed from their homes either because of the behavior of the parent, the behavior of the child, or both. In the AFCARS data, multiple reasons for removal can be indicated for each child. Most of the reasons for removal are attributable to the behavior of the parents. For instance, almost half of the children were removed as a result of neglect. Nearly one quarter of the children experienced either physical or sexual abuse, while more than $17 \%$ report removal as a result of parental drug addiction or alcoholism. Fewer of the children are removed as a result of their own actions. Behavior problems of the child are cited as a reason for removal in approximately $10 \%$ of the cases, while substance abuse by the child accounts for only $3 \%$ of removals. Children removed as a result of their own drug or alcohol use are most likely to be found in group homes, while those who were removed because of parental substance use are more likely to be placed with families.

Our regression models collapse the reasons for removal into two dichotomous variables. The first indicates that the child's behavior was identified as a reason for removal, and the second indicates that the parent's behavior was listed as a reason for removal. A foster child's case record can indicate multiple reasons for removal, or it can indicate no reason for removal. Thus, the child and parental reasons for removal indicators are neither mutually exclusive nor exhaustive. As reported in Table 3,85\% of the children's records indicate a parental reason for removal, while $20 \%$ indicate a child-related reason for removal.

In addition to the characteristics of the child and the circumstances surrounding his/her removal from the home, states are required to track the child's experiences while in foster care. Specifically, our data include indicators of how many times a child was moved to a new foster care setting during his or her first year in foster care. Overall, 58\% of the children in our full sample remained in their initial placement throughout their first year. The average child experienced 0.81 moves. There are only small differences in the number of placement moves across placement types. The AFCARS data also indicate that $2.6 \%$ of children in our sample of 1998 entrants to foster care have had their parents' rights terminated during that year, paving the way for adoption.

\section{Results}

\section{Type of Foster Care Setting}

Table 4 presents multinomial logit estimates of the determinants of a child being placed with relatives, with a foster family, or in a group home. Table 4 contains the results of four 


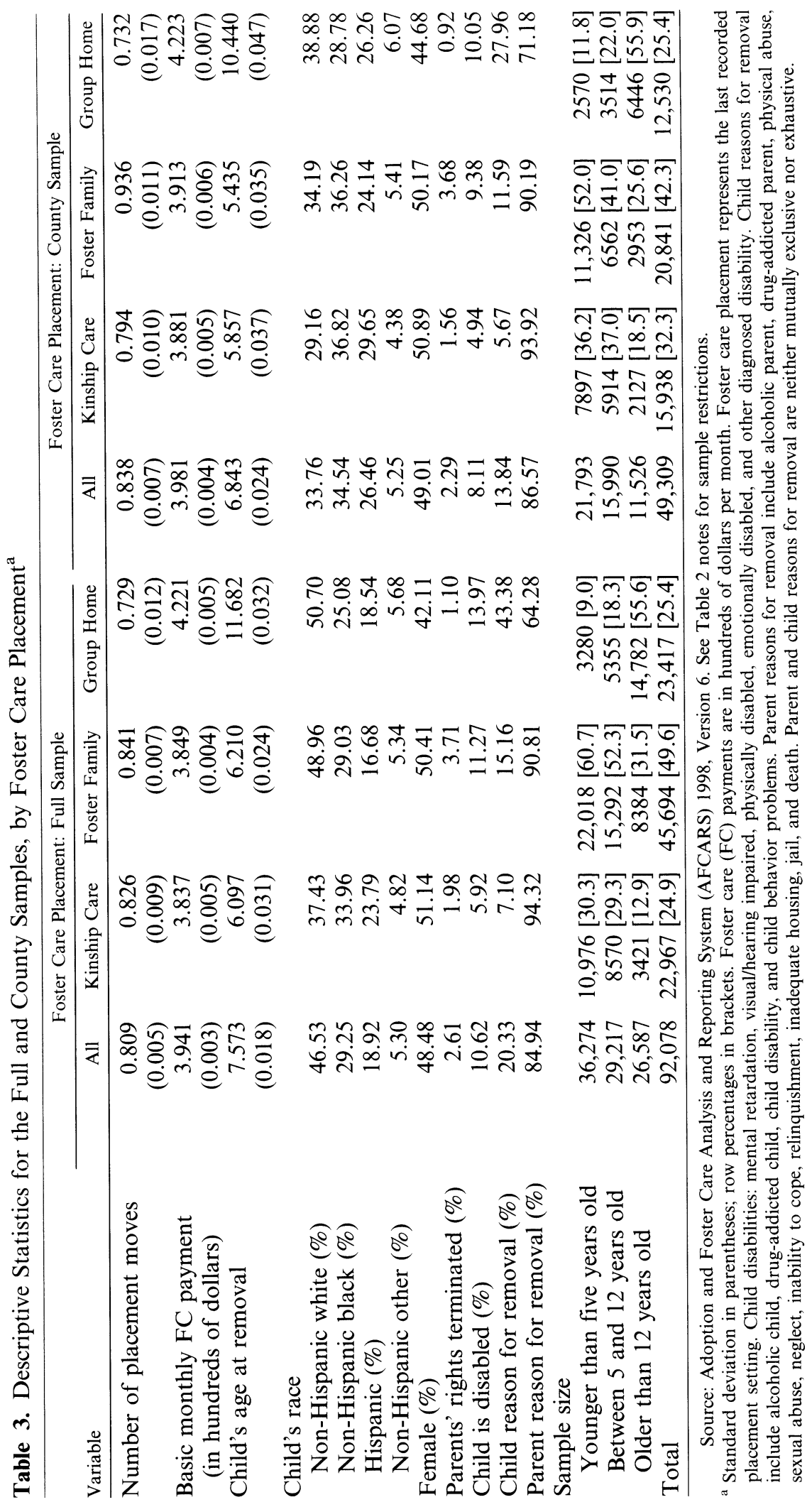




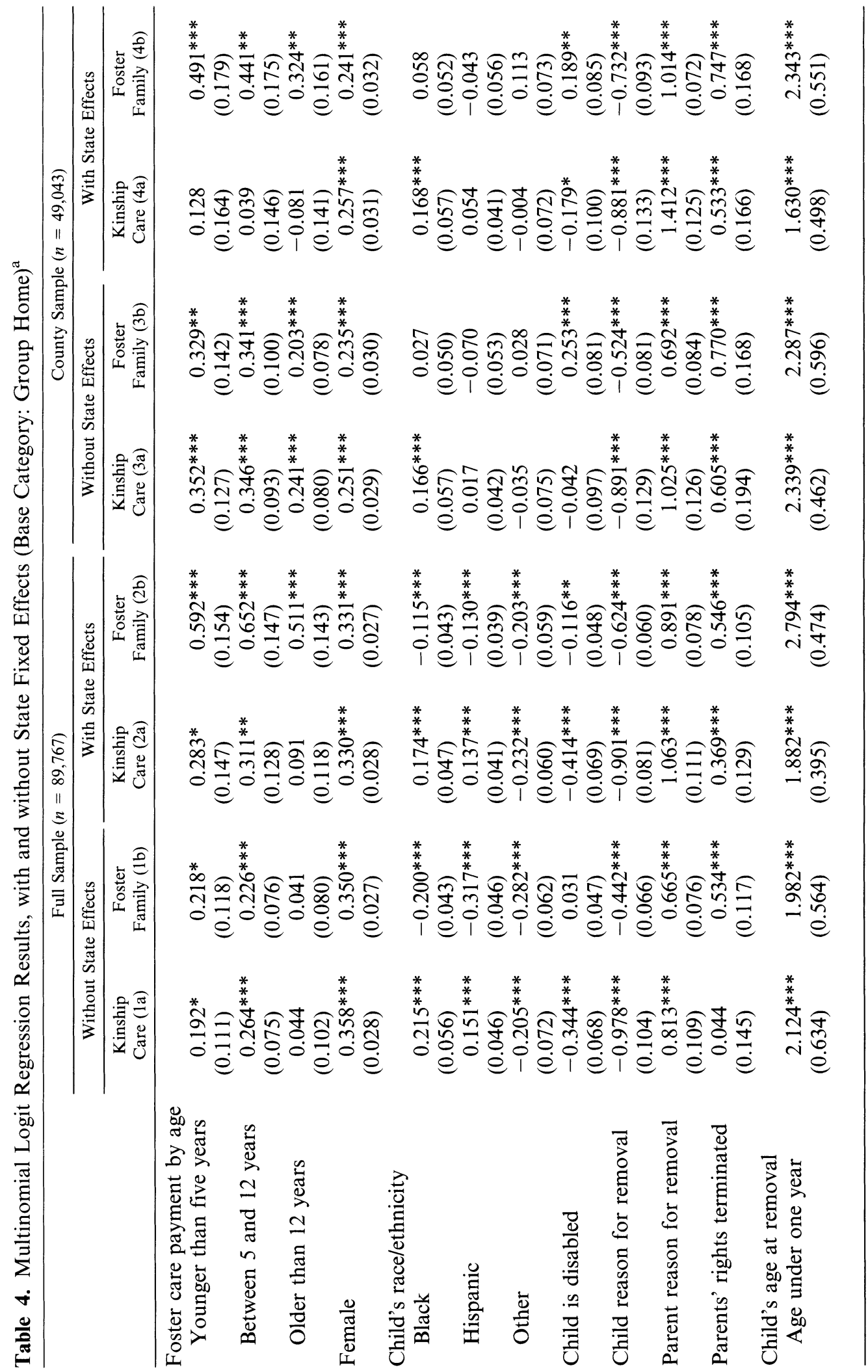




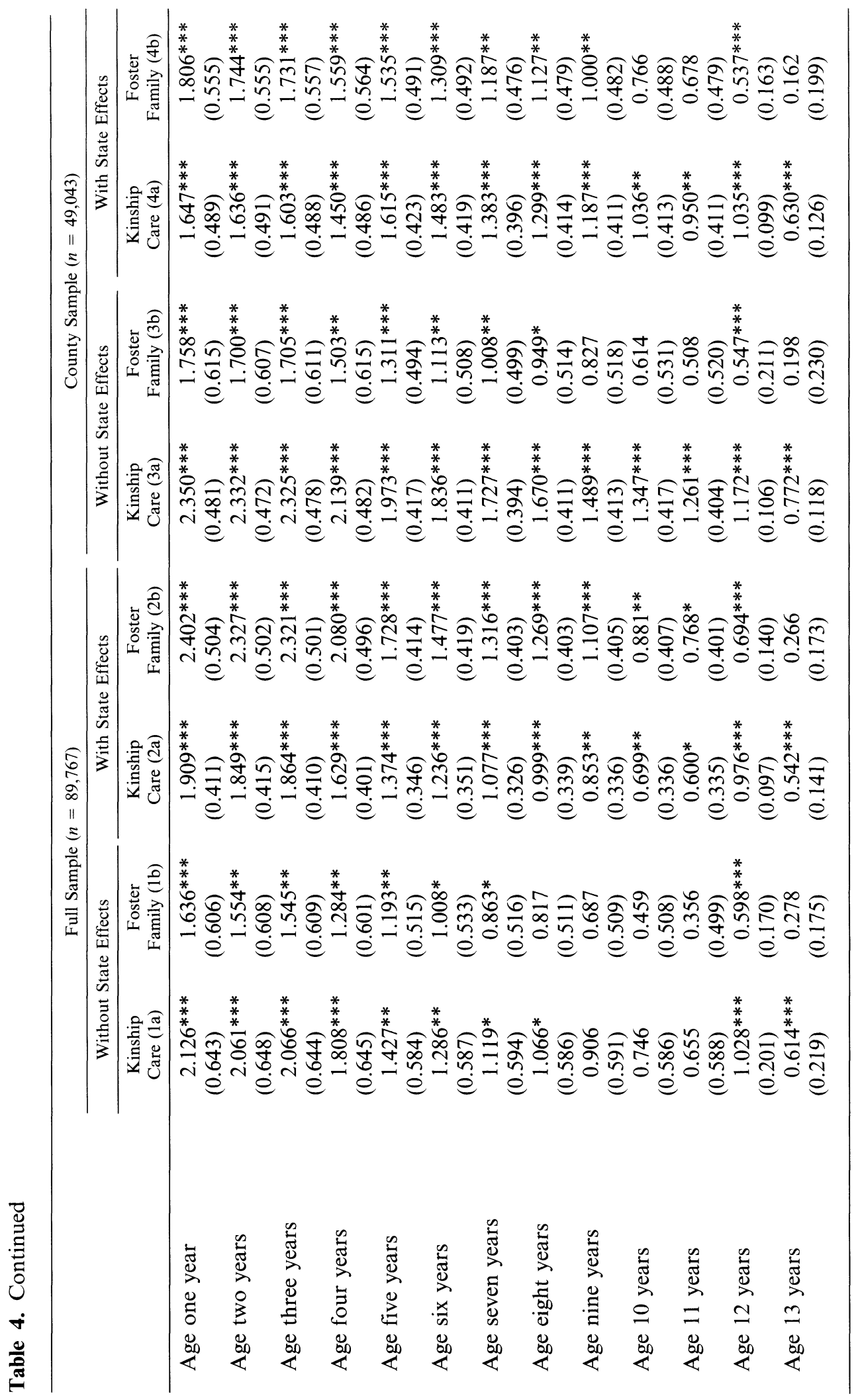




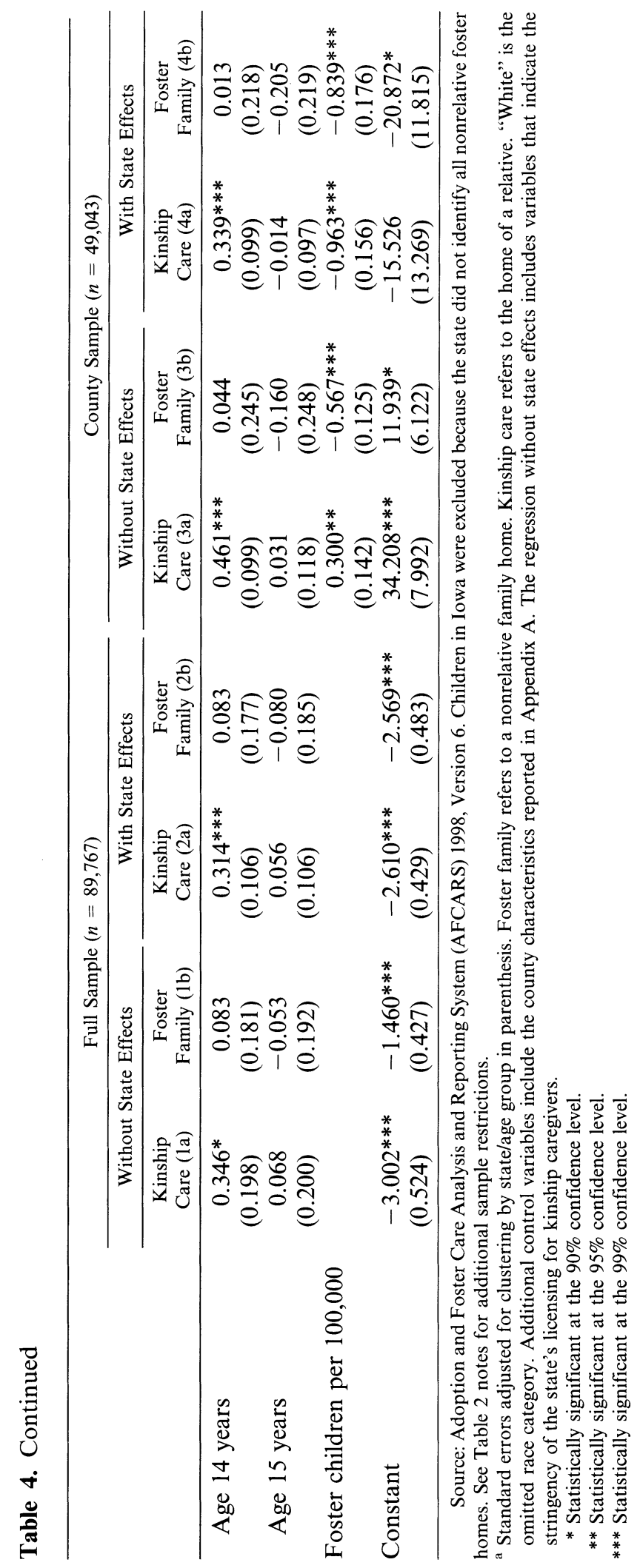


separate multinomial logit regressions, with placement in a group home as the base category. The coefficients are estimated for both the full sample and the county subsample with and without state effects. For example, for the full sample, columns $1 \mathrm{a}$ and $1 \mathrm{~b}$ report the multinomial logit coefficients from Equation 4 that do not control for state effects, and columns $2 \mathrm{a}$ and $2 \mathrm{~b}$ report estimates for the same model but controlling for state effects (and omitting the state policy variables described in footnote 12). Columns $3 a$ and $b$ and $4 a$ and b contain corresponding multinomial logit estimates estimated from the county subsample. Although the coefficients are not reported, both of the models estimated from the county subsample include the county characteristics listed in Appendix A.

It is clear from the results in Table 4 that characteristics of the child play an important role in determining foster care placement. Specifically, girls and younger children are more likely to be placed in a family setting and are least likely to be placed in a group home. In keeping with the findings reported in Berrick (1997), blacks and Hispanics are more likely than whites to be placed in kinship care (although the effect for Hispanic children does not reach conventional levels of significance in the county subsample). According to the models that include state effects, children with disabilities are less likely to be placed with relatives. Children whose behavior is indicated as the reason for removal from the home are less likely to be placed in either family setting and are more likely to be placed in a group home. Conversely, children removed for parental reasons are more likely to be placed in a family setting and less likely to be placed in a group home.

Turning now to the effect of foster care policies, Table 4 presents the results of the regression that allows the effect of the foster payment to vary by the child's age. We see that foster care payments have a significant effect on the type of foster care placement. Specifically, higher foster care payments are associated with an increase in a child's probability of being placed with an unrelated foster family. Estimates of the effect of state policies in columns 1a and $b$ and $3 a$ and $b$ are identified primarily through the variation in subsidy levels across states. As discussed earlier, policy effects may be biased in cross-sectional analyses if the policies are correlated with state-specific characteristics that are related to placement decisions or reporting patterns. Columns $2 \mathrm{a}$ and $\mathrm{b}$ and $3 \mathrm{a}$ and $\mathrm{b}$ report the results of the specification that controls for state effects. In both specifications, more generous subsidies are associated with higher probabilities of placement with a relative or with a foster care family than in a group setting.

As expected, tests of the joint significance of the state effects strongly reject the hypothesis that the state effects are jointly insignificant in both the full sample and in the county subsample. Thus, from this point on, we only report the results of regressions that include state fixed effects.

\section{Marginal Effects}

The magnitudes of the multinomial logit coefficients are difficult to interpret in any meaningful sense, and so in Table 5 we present marginal effects calculated from the multinomial logit regressions. These marginal effects measure the impact of a $\$ 100$ increase in foster care payments on the probability that a child with the average characteristics will be placed in a given setting. For both the full sample and county subsample, Table 5 presents the marginal effects estimated from five separate multinomial logit regressions. Model 1 estimates the overall effect that foster care payments have on child placement. Models 2 through 5 


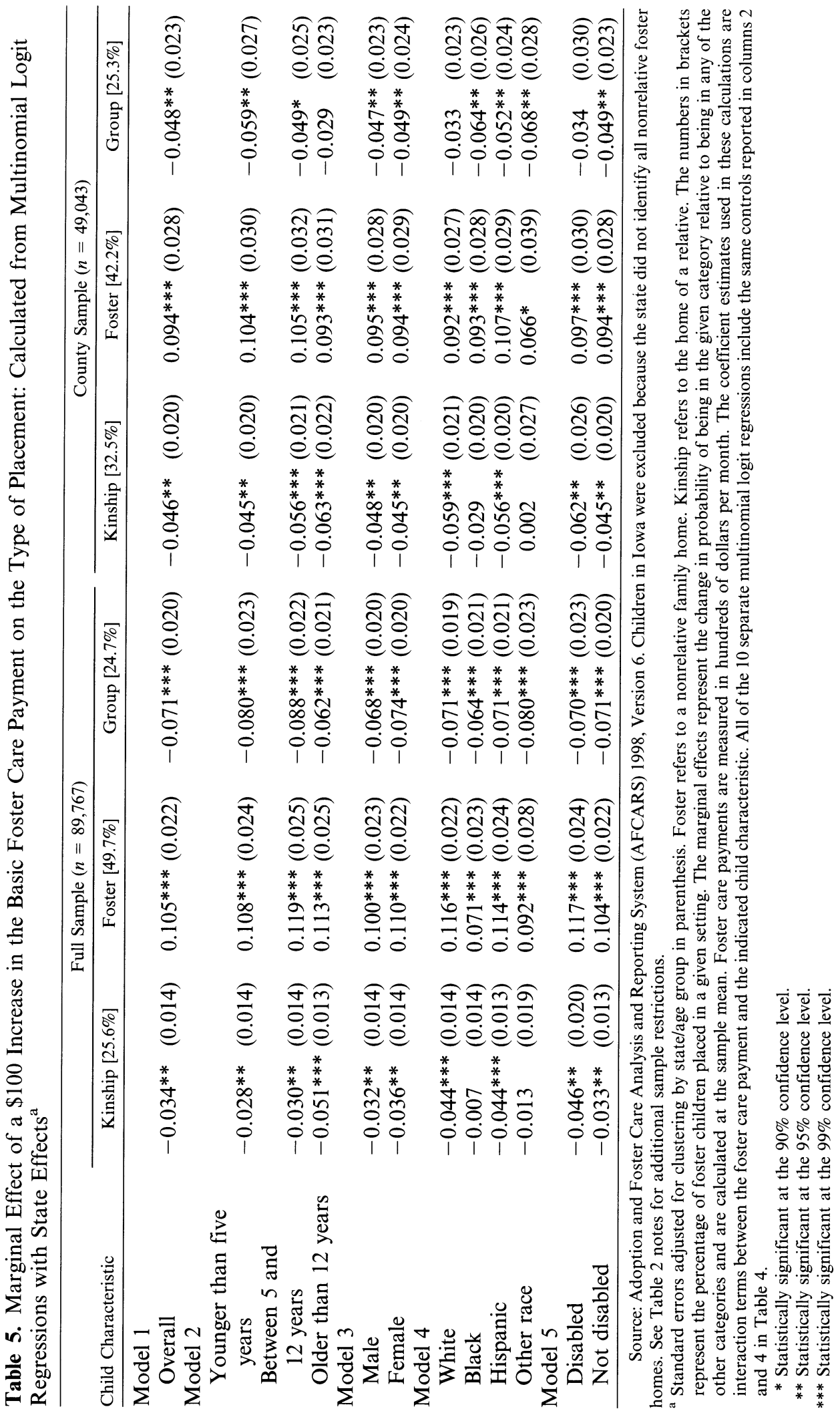


estimate this effect separately for the indicated child characteristic. For example, each set of marginal effects is calculated from a separate multinomial logit regression that includes interaction terms between the foster care payment and the specified child characteristic. Each regression also includes the same control variables listed in Table 4.

All of the marginal effects indicate that increasing the basic foster care subsidy decreases the probability that a child will be placed in a group home. Specifically, model 1 indicates that a $\$ 100$ increase in the basic monthly foster care payment will increase the probability that a child with the average characteristics will be placed with an unrelated foster family by $10.5 \%$ in the full sample and by $9.4 \%$ in the county subsample. In both cases, most of the children moved into unrelated foster homes would come from group homes ( $7.1 \%$ and $4.8 \%)$, but some would come from the homes of relatives (3.4\% and $4.6 \%$ ). These movements are substantial. Because $24.7 \%$ of all children who entered foster care in 1998 were placed in group homes, the $\$ 100$ increase in monthly subsidies would reduce the fraction of children in group settings by $28.7 \%$.

As seen from model 2 of Table 5, this effect is slightly larger for children younger than five years of age and for those between 5 and 12 years of age and is slightly smaller for children older than 12 years of age. As seen in model 3, the marginal effect of foster care payments is very similar for males and females. In fact, all of the analysis that follows indicates that basic foster care payments have the same effect on boys and girls. However, foster care payments seem to affect white and nonwhite children differently, particularly for the children in the county subsample. That is, for the full sample, an increase in foster care payments will pull approximately the same percentage of whites and blacks out of group homes (a 7.1\% reduction for whites and a $6.4 \%$ reduction for blacks). Both the white and black children pulled out of group homes will be placed in foster homes. However, an increase in foster care payments will also pull white children out of kinship care, but not black children. As a result, a $\$ 100$ increase in foster care payments will increase the number of white children in foster homes by $11.6 \%$ and the number of black children in foster homes by $7.1 \%$.

The estimates from the county subsample are similar to those from the full sample with regard to race, except for white children. In the county subsample, a $\$ 100$ increase in foster care payments will decrease the number of black children in group homes by $6.4 \%$ (the same amount as in the full sample) but will decrease the number of white children in group homes by only $3.3 \%$. This result indicates that increasing foster care payments will be more effective at moving white children out of group homes in rural areas than in urban areas.

Finally, model 5 in Table 5 shows that foster care payments have a similar effect on the placement of disabled and nondisabled children. In the full sample, a $\$ 100$ increase in foster care payments will decrease the number of disabled and nondisabled children placed in group homes by $7 \%$. The corresponding estimates from the county subsample are about half this size. This is indicative of the relationship between the estimates from the full sample and the county subsample. The general pattern of results is the same in both samples; however, the estimates from the county subsample are generally smaller than those from the full sample.

The overall pattern of results presented in Table 5 indicates that increased foster care subsidies move children into nonrelated foster family homes and out of both group homes and kinship care. While moving children out of group homes is generally considered a positive result, the relative merits of moving children out of relative care are less clear. It is possible that, as more foster homes become available, caseworkers weigh the opportunities provided by relatives with those available from nonrelated foster family and selectively move children whose 
relatives face health problems or financial challenges to a foster family. This behavior, however, is inconsistent with the 1996 Coats Amendment, which states that placement with relatives should be given priority.

\section{Other Foster Care Outcomes}

Having established that more generous foster care subsidies increase the likelihood that a child is placed with a family rather than in a group home, we turn our attention to other dimensions of the foster care placement decision. Specifically, we examine whether subsidy levels affect placement characteristics such as whether the child is placed with a caretaker who is of the same racial or ethnic group, the number and gender of the foster parents, and the stability of the placement, as measured by the number of times a child was moved to another placement setting in 1998.

Whether racial and ethnic matching between children and their foster parents should be a priority is an unresolved issue. Proponents of racial matching have argued that preservation of a child's culture and heritage are important and should be considered when removing a child from her home. Though most adoptions and foster care placements involve the same race, the Multiethnic Placement Act of 1994 made it illegal to delay adoptions in order to match the racial or ethnic background of the child. The consequences of transracial adoption and foster placement are largely unknown.

Our data include indicators of the race and ethnicity of the caretaker(s) and the child. Caretaker race and ethnicity are not recorded for children in group homes, and so we continue to treat these children as a separate group. We consider a race/ethnicity match to have occurred if the child's race is the same as that of any of his or her caretakers. We also consider a race/ ethnicity match to have occurred when a Hispanic child is placed with a Hispanic parent. The caregiver's race is typically not recorded for children placed with relatives. In these cases, we assume that the child and his or her relatives share the same race/ethnicity. We also include a third category for the substantial number of children for whom we are unable to ascertain whether or not there is a racial match because the caretaker's race and/or ethnicity are not reported.

Table 6 reports estimated marginal effects of foster care subsidies from multinomial logit models similar to those described in the preceding section, where the categories of the dependent variable now are racial/ethnic match, racial/ethnic mismatch, racial/ethnic unknown, and placement in a group home. ${ }^{16}$ All of the models in Table 6 include the same independent variables as the model reported in Table 5. Consistent with the earlier results, all of the estimates reported in Table 6 indicate that a $\$ 100$ increase in the basic monthly foster care payment will pull children out of group homes. The estimates further indicate that these children will be disproportionately placed with caregivers who do not share the child's race or ethnicity. For example, in the full sample, a $\$ 100$ increase in the basic monthly foster care payment is associated with a $3.7 \%$ increase in the probability of a race/ethnic match and a $2.3 \%$ increase in the probability of a race/ethnic mismatch. These increases are disproportionate because in the full sample, $53.9 \%$ of children have a race/ethnic match, while only $7.8 \%$ of children have a race mismatch. Therefore, a $\$ 100$ increase in the foster care payment is

\footnotetext{
${ }^{16}$ Estimated coefficients for all variables contained in the model are available from the authors upon request.
} 
associated with a $6.9 \%$ increase in the number of children with a race/ethnicity match and a $29.5 \%$ increase in the number of children with a race/ethnicity mismatch. We find similar patterns among very young children and among children between the ages of 5 and 12 years. However, for children older than 12 years, an increase in foster care payments is not associated with an increase in the probability of a race/ethnicity match, but rather is associated with an increase in the probability of a race/ethnicity mismatch.

Foster care payments seem to have the same effect on the racial-match probabilities of males and females. However, the marginal effects vary considerably by the race/ethnicity of the child. In fact, the pattern of moving children out of group homes and disproportionately into race/ethnicity mismatches is stronger for whites than it is for blacks. This result may be related to the results in the previous section. That is, the results in Table 5 indicate that increasing foster care payments will reduce the number of white children placed with relatives, but not the number of black children placed with relatives. Thus, for white children, increasing foster care payments is associated with a reduction in the probability of a race/ethnic match, in part because it is associated with a reduction in the probability that a white child will be placed with a relative. The same is not true for black children.

In our final multinomial logit specification, we examine the impact of foster care subsidies on family structure in the placement setting. Each child in the AFCARS data is identified as residing in foster care with two parents, one parent, or an unknown number of parents or in a group home. In the full sample, $28.8 \%$ of children are placed in two-parent homes, while $31.5 \%$ are placed in single-parent homes. The overwhelming majority of single foster parents are women (over $80 \%$ ). Children in the county subsample are much more likely to be placed in a single-parent home (42.7\%) than in a two-parent home (17.8\%). This represents the greatest difference between the full sample and the county subsample. The county subsample contains large counties that appear to rely more heavily on single-parent foster homes. As can be seen in Table 7, all of the estimated marginal effects indicate that a $\$ 100$ increase in the basic monthly foster care payment will pull children out of group homes, which is again consistent with the earlier results. Nearly all of the estimates from the full sample indicate that the children pulled from groups homes are equally likely to be placed in two-parent and single-parent homes. For example, in the full sample, a $\$ 100$ increase in the basic monthly foster care payment is associated with a $4.4 \%$ increase in the probability of a child being placed in a single-parent home and a $4.0 \%$ increase in the probability of a child being placed in a two-parent home. In the county subsample, a $\$ 100$ increase in the basic monthly foster care payment is associated with a $5.1 \%$ increase in the probability of a child being placed in a single-parent home, but is not associated with any increase in the probability of a child being placed in a two-parent home. As seen in Table 7, these results are fairly consistent across age, gender, race, and disability.

\section{Number of Placement Moves}

In our final analysis, we investigate whether more generous foster care payments lead to more stable placements. Policy makers and professionals dedicated to ensuring a developmentally beneficial environment for each foster child point to the need to avoid the foster care "drift" that occurs when children are frequently moved from one foster care setting to another. The American Association of Pediatrics released a statement indicating that "[m]ultiple foster home placements can be injurious" to children (USA Today Magazine 2001). Child 


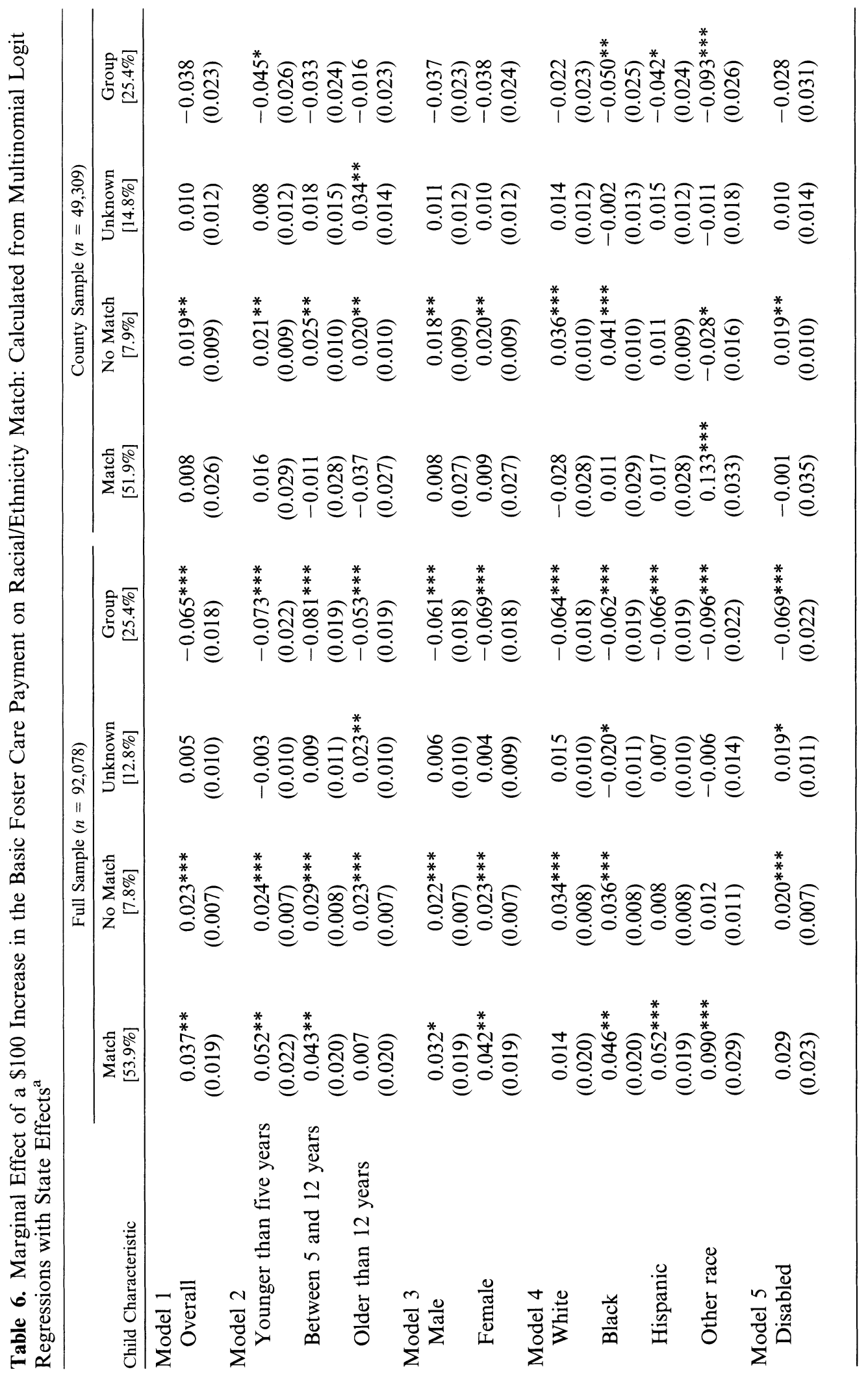




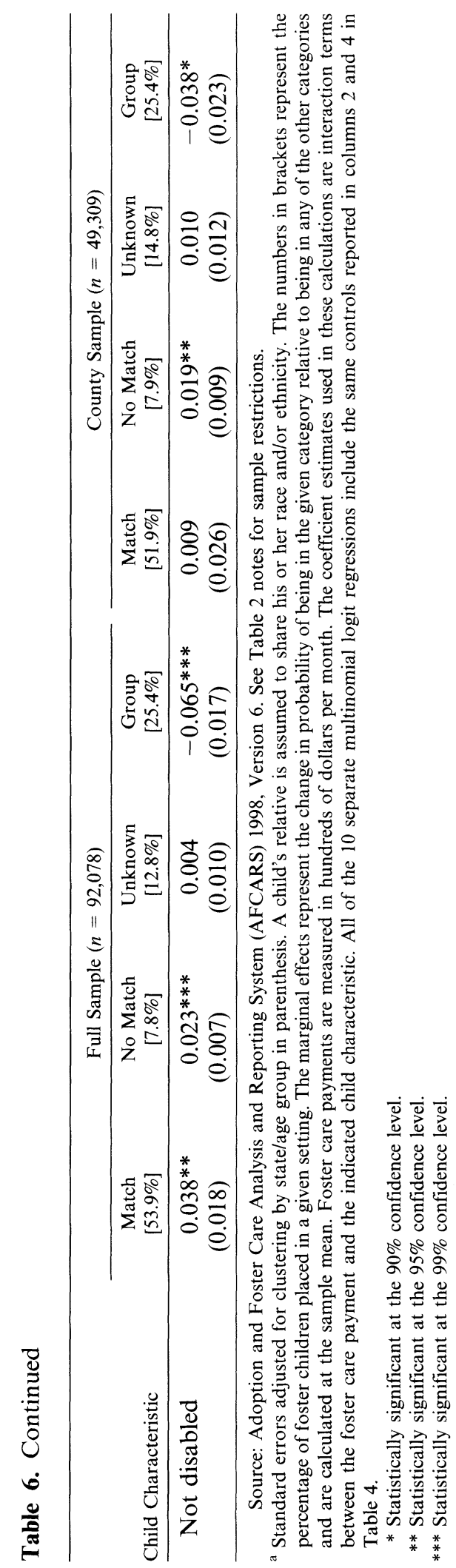




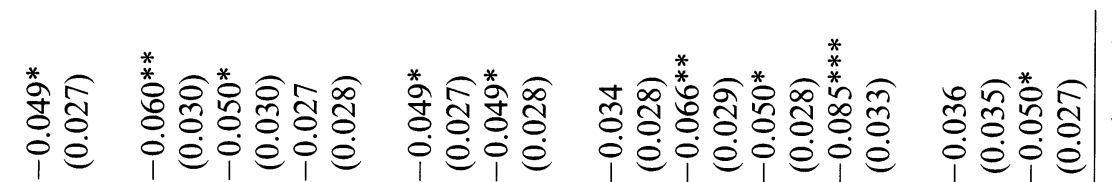
í $\dot{0} \dot{0} \dot{0} \dot{0} \dot{0}$

i

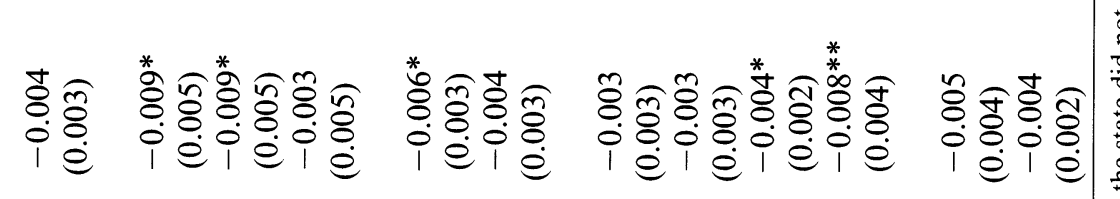

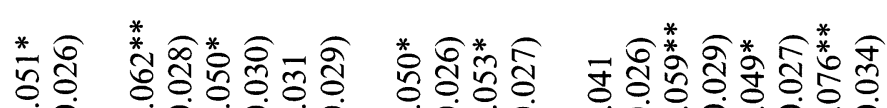

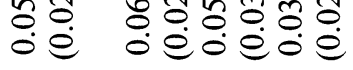
○ं

ن.

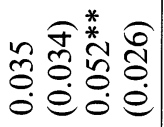

ธิธิ์

ํํㅇㅎํ융

ఫิ

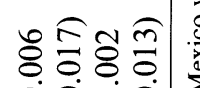

ó $\dot{e} \dot{0} \dot{0} \dot{0}$ ○윙

i $0 \dot{0} 0 \dot{0} 0$

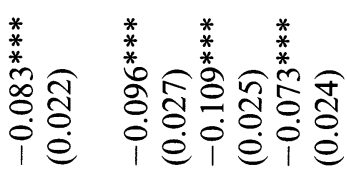

\section{$\stackrel{*}{2} \overbrace{*}^{*} \stackrel{*}{*}$}

$\stackrel{*}{*} \stackrel{*}{*} \stackrel{*}{*} \stackrel{*}{*} \stackrel{*}{*} \underset{*}{*} \widetilde{*}$ $\circ 00$

융ํㅇㅇํ.

i

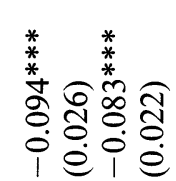

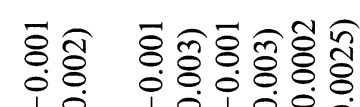

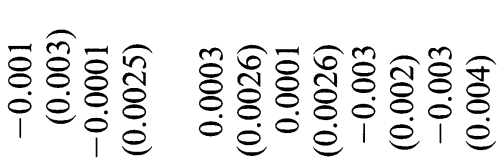

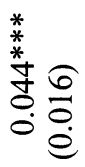

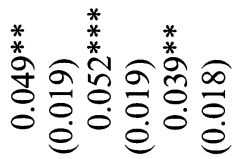

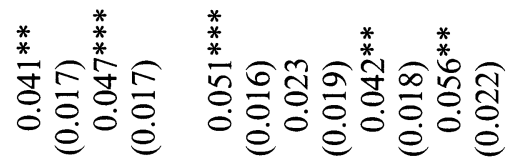

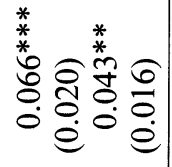

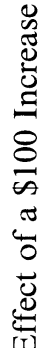

$\overline{0}$
$\infty$
$\infty$
0
$\vdots$
0
0
0
0
0

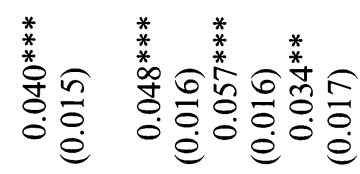

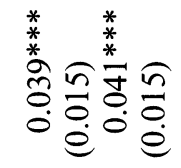

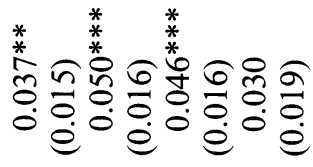

훙ㅎㅇㅇㅎㅇㅎㅇ

它

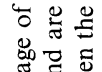

苛

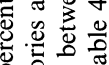

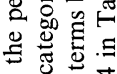

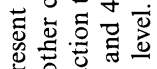

范

政

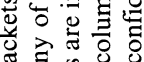

近表嵒造

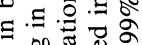

帘.

잉

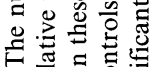

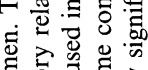

3 论

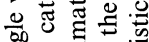

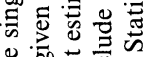

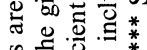

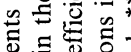

可 $\Xi 0.0$

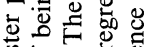

웅

कo 3

के

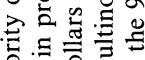

응 혛

중

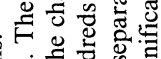

.

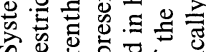

苋递它品

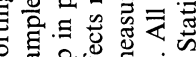

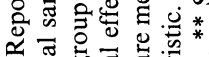

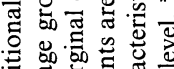

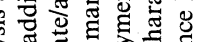

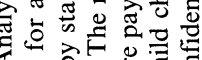

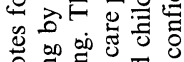

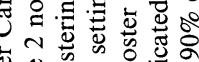

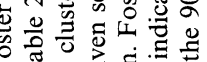

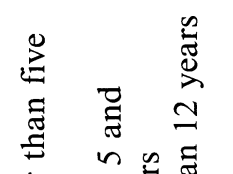

$\sum^{\sigma}$

$\therefore$

品

- = $\sim$ 茄的志氧

范

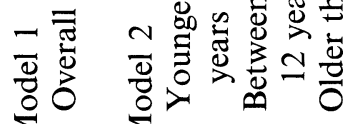

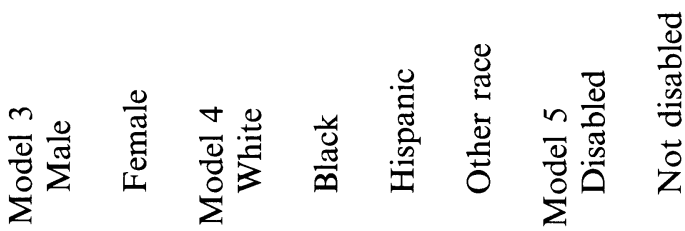

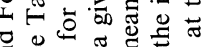

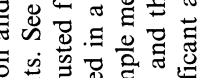

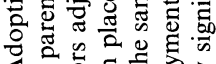

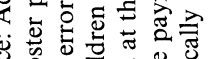

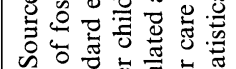

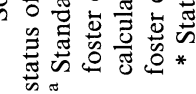


development researchers suggest that multiple placements result in unstable adult-child relationships that damage a child's ability to form attachments to significant others (Usher, Randolph, and Gogan 1999).

As reported in Table 3, the average child in the full sample experiences 0.809 placement moves $(0.838$ in the county subsample). Table 8 reports the marginal effect of a $\$ 100$ increase in the basic monthly foster care payment on the number of placement moves in 1998. These marginal effects are estimated using both an OLS model and a Poisson regression model. All of the marginal effects estimates indicate that foster care payments are negatively associated with the number of placement moves. For example, the Poisson regressions indicate that a $\$ 100$ increase in the basic monthly foster care payment is associated with 0.159 and 0.175 reductions in the number of placement moves in the full sample and county subsamples, respectively. Both estimates represent a $20 \%$ reduction in the number of placement moves. These results are fairly consistent across gender, race, and disability, although the effect is slightly larger for older children than it is for younger ones.

\section{Conclusions}

Policy makers have directed state child welfare agencies to selectively place foster children in settings deemed to be the most beneficial. The preferences expressed in recent legislation encourage placement with relatives, in preadoptive homes, and with unrelated foster families rather than in group settings. States may be handcuffed in their ability to meet this mandate if the supply of family placements cannot meet the demand.

This study is the first to address the responsiveness of foster care settings to financial incentives in the form of increased monthly subsidies. Using individual-level data from the AFCARS combined with data on state foster care subsidy levels from the Child Welfare League of America, we estimate multinomial logit models of the probability of placement in three foster care settings: a relative's home, the home of an unrelated foster family, or a group or institutional foster care facility. Our results indicate that group placement becomes increasingly unlikely as foster care subsidy levels rise. Specifically, our full sample estimates indicate that a $\$ 100$ increase in the basic monthly foster care payment will reduce the number of children placed in group homes by $28.7 \%$. To a lesser extent, it will also reduce the number of children placed with relatives. The children pulled out of group homes will be disproportionately placed with caregivers who do not share the child's race or ethnicity. The same $\$ 100$ increase in foster care payment will also decrease the average foster child's number of placements by $20 \%$.

Our results indicate that the amount of financial compensation does have a statistically significant effect on a family's willingness to take in a foster child. While the magnitude of the effect is not trivial, policies designed to move children out of group homes by increasing basic foster care payments across the board may not be cost effective. For instance, our results indicate that a $\$ 100$ increase in foster care payments would reduce the percentage of children placed in group homes from $24.7 \%$ to $16.4 \%$. Of the 91,122 children in our full sample, the number of children placed in group homes would fall from 22,507 to $14,944 .{ }^{17}$ While the $\$ 100$

\footnotetext{
${ }^{17}$ Certainly it would not be desirable to move all children from group care to a family setting. Though the proportion for whom this option is most beneficial is unknown, in some cases, group foster care provides the most beneficial therapeutic environment. Our simulation leaves $16 \%$ of children in group settings.
} 
Table 8. Marginal Effects of a $\$ 100$ Increase in the Basic Foster Care Payment on the Number of Placement Moves: Calculated from OLS and Poisson Regressions with State Effects ${ }^{\mathrm{a}}$

\begin{tabular}{|c|c|c|c|}
\hline \multirow[b]{2}{*}{ Child Characteristic } & \multicolumn{2}{|c|}{ Full Sample $(n=92,078)$} & County Sample $(n=49,309)$ \\
\hline & OLS & Poisson & Poisson \\
\hline \multicolumn{4}{|l|}{ Model 1} \\
\hline Overall & $-0.267 * * *(0.024)$ & $-0.159^{* * *}(0.012)$ & $-0.290^{* * *}(0.036)-0.175^{* * *}(0.017)$ \\
\hline \multicolumn{4}{|l|}{ Model 2} \\
\hline $\begin{array}{l}\text { Younger than } \\
\text { five years }\end{array}$ & $-0.261 * * *(0.025)$ & $-0.150^{* * *}(0.012)$ & $-0.272^{* * *}(0.036)-0.154 * * *(0.017)$ \\
\hline \multicolumn{4}{|l|}{ Between 5 and } \\
\hline 12 years & $-0.276^{* * *}(0.028)$ & $-0.173 * * *(0.015)$ & $-0.294 * * *(0.042)-0.181 * * *(0.022)$ \\
\hline \multicolumn{4}{|l|}{ Older than } \\
\hline 12 years & $-0.276^{* * *}(0.026)$ & $-0.181^{* * *}(0.014)$ & $-0.338^{* * *}(0.040)-0.231^{* * *}(0.020)$ \\
\hline \multicolumn{4}{|l|}{ Model 3} \\
\hline Male & $-0.274 * * *(0.025)$ & $-0.168^{* * *}(0.012)$ & $-0.302^{* * *}(0.037)-0.192^{* * *}(0.017)$ \\
\hline Female & $-0.259 * * *(0.025)$ & $-0.150 * * *(0.012)$ & $-0.277 * * *(0.037)-0.157 * * *(0.017)$ \\
\hline \multicolumn{4}{|l|}{ Model 4} \\
\hline White & $-0.262 * * *(0.025)$ & $-0.154 * * *(0.012)$ & $-0.296^{* * *}(0.037)-0.182^{* * *}(0.018)$ \\
\hline Black & $-0.259 * * *(0.026)$ & -0.143 & $-0.263 * * *(0.039)-0.140 * * *(0.019)$ \\
\hline Hispanic & $-0.273 * * *(0.0$ & $*(0.014)$ & $-0.281 * * *(0.038)-0.174 * * *(0.019)$ \\
\hline Other race & $-0.293 * * *(0.037)$ & $-0.187 * * *(0.019)$ & $-0.356^{* * *}(0.054)-0.233^{* * *}(0.028)$ \\
\hline \multicolumn{4}{|l|}{ Model 5} \\
\hline Disabled & $-0.260 * * *(0.029)$ & $-0.154^{* * *}(0.015)$ & $-0.344 * * *(0.045)-0.208^{* * *}(0.022)$ \\
\hline Not disabled & $-0.267 * * *(0.024)$ & $-0.159 * * *(0.012)$ & $-0.286^{* * *}(0.036)-0.171^{* * *}(0.017)$ \\
\hline
\end{tabular}

Source: Adoption and Foster Care Analysis and Reporting System (AFCARS) 1998, Version 6. See Table 2 notes for sample restrictions.

${ }^{a}$ Standard errors in parentheses. Marginal effects are calculated at the mean of the data. Foster care payments are measured in hundreds of dollars per month. The coefficient estimates used in these calculations are interaction terms between the foster care payment and the indicated child characteristic. All 10 of the regressions reported include the same controls as those reported in columns 2 and 4 in Table 4.

* Statistically significant at the $90 \%$ confidence level.

** Statistically significant at the $95 \%$ confidence level.

$* * *$ Statistically significant at the $99 \%$ confidence level.

increase in the foster care payment would move 7563 children out of group homes, if it was provided for the care of all of the children in our sample, it would cost approximately 9.11 million dollars per month. That translates into a cost of $\$ 1205$ per child moved out of a group home.

By increasing payments for all children in foster care, the preceding cost-benefit analysis portrays the most expensive scenario and highlights the fact that policies designed to move children out of group homes should, to the extent possible, be targeted at specific groups of children. The best-case scenario would have the increase in foster care payments be provided only for children that are moved out of group homes. While this best-case scenario may not be feasible, foster care agencies can and do provide additional compensation for children that they deem to have special needs. A policy designed to move children out of group homes could expand the definition of "special needs" to include children who are currently being placed in group homes but who are candidates for a foster home placement. For example, as noted above, foster care payments vary by the age of the child, and so placements for children of a particular age group could be targeted by policy makers.

Finally, our results indicate that the financial compensation paid by states can have a significant impact on the experiences of children in foster homes. For the most part, states 
were able to maintain the real value of their foster care payments during the 1990s. However, recent state budgetary shortfalls have forced states like South Carolina and Oregon to reduce their foster care payments. If this trend spreads to other states, we can expect to see more foster children placed in group homes, as well as an increase in the average number of placements experienced by foster children.

\section{Appendix A}

Sample Means of County Variables ${ }^{\mathrm{a}}$

Foster children per 10,000 population

Population per square mile (in thousands)

10 -Year population growth $(\%)$

Population aged $0-17$ years $(\%)$

Males per 100 females

Black only $(\%)$

Hispanic (\%)

Median age (years)

Households headed by female $(\%)$

$0.913(0.494)$

$2.015(2.299)$

$13.165(9.375)$

$26.863(2.712)$

$97.072(3.779)$

$12.743(13.386)$

$23.340(15.011)$

$33.448(1.940)$

$13.627(3.012)$

Female-headed household with children (\%)

$58.519(5.016)$

Graduated high school (\%)

$76.331(6.923)$

Graduated college (\%)

Median household income (in thousands of dollars)

$33.325(6.024)$

10 -Year median income growth $(\%)$

$20.077(11.469)$

Population under the poverty level $(\%)$

$15.389(4.912)$

18 Years and younger under the poverty level $(\%)$

$23.307(7.073)$

Serious crimes known to police per 1000 population

$10.659(26.018)$

Unemployment rate $(\%)$

Sample size

$4.751(2.699)$

49,309

Source: City and County Data Book (2000; U.S. Census Bureau)

${ }^{a}$ Standard deviation in parentheses.

\section{References}

Berrick, Jill Duerr. 1997. Assessing quality of care in kinship and foster family care. Family Relations 46:273-80.

Boots, Shelly Waters, and Rob Geen. 1999. Family care or foster care? How state policies affect kinship caregivers. In New federalism: Issues and options for states, No. A-34. Washington, DC: Urban Institute. Available http:// www.urban.org/publications/309166.html.

Buehler, Cheryl, John G. Orme, James Post, and David A. Patterson. 2000. The long-term correlates of foster care. Child and Youth Services Review 22(8):595-625.

Campbell, Claudia, and Susan Whitelaw Downs. 1987. The impact of economic incentives on foster parents. Social Service Review 61(5):599-609.

Chamberlain, Patricia, Sandra Moreland, and Kathleen Reid. 1992. Enhanced services and stipends for foster parents: Effects on retention rates and outcomes for children. Child Welfare 71(5):387-401.

Doyle, Joseph J. 2004. Can't buy me love? Subsidizing the care of grandchildren. Unpublished paper, MIT.

Doyle, Joseph J., and H. Elizabeth Peters. 2002. The market for foster care: An empirical study of the impact of foster care subsidies. Unpublished paper, Cornell University.

Festinger, T. 1983. No one ever asked us: A postscript to foster care. New York: Columbia University Press.

Guggenheim, Martin. 1999. The foster care dilemma and what to do about it? Is the problem that too many children are not being adopted out of foster care or that too many children are entering foster care? University of Pennsylvania Journal of Constitutional Law 2(1):141-9. 
Kelley, S. J. 1992. Parenting stress and child maltreatment in drug-exposed children. Child Abuse and Neglect 16(3):317-28.

Lowery, M. 2000. Foster care and adoption reform legislation: Implementing the Adoption and Safe Families Act of 1997. St. John's Journal of Legal Commentary 14(3):447-57.

Mnookin, Robert H. 1973. Foster care: In whose best interest? Harvard Education Review 43(4):599-638.

Moulton, Brent R. 1990. An illustration of a pitfall in estimating the effects of aggregate variables on micro units. The Review of Economics and Statistics 72(2):334-8.

National Data Archive on Child Abuse and Neglect. 2002. Adoption and foster care analysis and reporting system (AFCARS), 1995-1999: User's guide and codebook. Ithaca, NY: Family Life Development Center, Cornell University.

Pagano, Celeste. 1999. Adoption and foster care. Harvard Journal on Legislation 36:242-9.

Ross, Catherine J., and Naomi R. Cahn. 2000. Subsidy for caretaking in families: Lessons from foster care. Journal of Gender, Social Policy and the Law 8(31):55-71.

Simon, Julian. 1975. The effect of foster care payment levels on the number of foster children given homes. Social Service Review 49:405-11.

USA Today Magazine. 2001. Recommendations to improve foster care. April. Available http://www.findarticles.com/p/ articles/mi_m1272/is_2671_129/ai_73236145.

Usher, Charles L., Karen A. Randolph, and Harlene C. Gogan. 1999. Placement patterns in foster care. Social Service Review 73:22-36.

Wald, Michael S. 1975. State intervention on behalf of neglected children: A search for realistic standards. Stanford Law Review 27(4):984-1040. 